\title{
SOBRE O NEOCONSTITUCIONALISMO E A TEORIA DOS PRINCÍPIOS CONSTITUCIONAIS
}

\author{
José Sérgio da Silva Cristóvam
}

Resumo: $O$ estudo aborda os contornos do neoconstitucionalismo, modelo teórico que propõe a superação do conjunto de teorias que marcam o positivismo jurídico, a partir da consolidação de um modelo fundado na prevalência da Constituição, na estreita relação entre o discurso jurídico e a argumentação moral, tudo informado pela firme defesa da força normativa dos princípios constitucionais. No neoconstitucionalismo, a teoria dos princípios constitucionais alcança especial relevância para o discurso jurídico contemporâneo, a ser acompanhada de uma sólida teoria da argumentação jurídica, capaz de assegurar critérios de racionalidade na aplicação daquele sistema aberto de princípios constitucionais, essencial

1 Doutorando em Direito Administrativo pela UFSC, com estágio de Doutoramento Sanduíche junto ao Instituto Superior de Ciências Sociais e Políticas (ISCSP) da Universidade Técnica de Lisboa (Portugal). Mestre em Direito Constitucional pela UFSC. Especialista em Direito Administrativo pelo CESUSC. Professor de Direito Administrativo da Escola Superior da Magistratura do Estado de Santa Catarina (ESMESC). Professor de Direito Administrativo da Escola Nacional de Administração (ENA/Brasil), em convênio com a École Nationale d'Administration (I'ENA/ França). Professor Titular de Ciência Política e Teoria Geral do Estado e Professor Substituto de Direito Administrativo no Curso de Graduação em Direito da UNIDAVI (Rio do Sul/SC), bem como em Cursos de Pós-Graduação em Direito da UNIDAVI, CESUSC, UNOESC, UNISUL, UnC e diversas outras instituições. Professor em cursos preparatórios para Concursos Públicos e Exames de Ordem, nas disciplinas de Direito Constitucional e Direito Administrativo. Membro fundador do Instituto de Direito Administrativo de Santa Catarina (IDASC). Assessor Jurídico do Sindicato dos Trabalhadores na Rede Estadual de Ensino de Santa Catarina (SINTE/SC). Advogado militante na seara do Direito Público, Sócio do Escritório Cristóvam \& Palmeira Advogados Associados S/C (www.cpadvogados.adv.br). E-mail: jscristovam@gmail.com 
fator de legitimação e justificação das decisões (discurso judicial). Estas são algumas das discussões inseridas no presente estudo. Por fim, conclui-se defendendo a relevância da temática abordada, inclusive para a consolidação de uma cultura de defesa da Constituição.

Palavras-chave: Neoconstitucionalismo. Pós-positivismo jurídico. Princípios constitucionais. Argumentação jurídica.

\section{INTRODUÇÃO}

A moderna noção de constitucionalismo vem sendo marcada, preponderantemente, pelo movimento de positivação em âmbito constitucional dos princípios gerais de Direito, sobretudo a partir com o advento do chamado Estado social de direito. Esse movimento migratório dos princípios jurídicos para as constituições, tanto pela assunção de princípios reconhecidos pela legislação infraconstitucional, como pela incorporação de princípios constitutivos do Direito Internacional, constitui-se em traço distintivo dos modelos constitucionais contemporâneos, a exemplo do que ocorre com a Constituição brasileira de 1988.

A força jurídica vinculante das constituições contemporâneas passa, de forma destacada, pela idéia de normatividade dos princípios constitucionais. Não se pode mais entender as normas constitucionais como simples ideários, expressões de anseios, aspirações de uma dada Sociedade. A força normativa da Constituição é condição inarredável à própria conservação do ordenamento jurídico².

O movimento de constitucionalização dos princípios jurídicos coincide com a defesa doutrinária da força normativa e vinculatividade dos princípios, em contraposição às idéias positivistas que dominaram, hegemonicamente, o discurso jurídico até a primeira metade do século XX. O uso dos princípios como

2 Para estudos complementares, consultar: HESSE, Konrad. A força normativa da Constituição. Tradução de Gilmar Ferreira Mendes. Porto Alegre: Sergio Antonio Fabris Editor, 1991. 
fonte normativa subsidiária, conforme defendido pelo positivismo jurídico, já não encontra mais guarida na teoria constitucional contemporânea. Essa é a pauta que informa o chamado pós-positivismo jurídico.

\section{O NEOCONSTITUCIONALISMO E A CONSOLIDAÇÃO DO PÓS-POSITIVISMO JURÍDICO}

A questão da normatividade dos princípios jurídicos guarda profunda relação com a superação do Estado liberal de direito, pautado pela lógica do positivismo jurídico, e a consolidação do "neoconstitucionalismo", como expressão do modelo conhecido como "pós-positivismo jurídico".

A expressão "neoconstitucionalismo" será aqui empregada com relação de sinonímia ao pós-positivismo jurídico, para caracterizar um modelo teórico que vem ganhando expressão e lastro na cultura jurídica a partir da segunda metade do século XX, baseado na superação das idéias que marcam o positivismo jurídico, principalmente no que concerne à relação de tensão entre Direito e moral ${ }^{3}$.

Não se pode desvincular as mudanças teóricas que respaldaram a passagem do positivismo jurídico para o pós-positivismo ou neoconstitucionalismo, das profundas mudanças sociais e econômicas do final do século XIX e do século XX. O positivismo jurídico, aqui entendido como aquela teoria jurídica que encara o direito positivo como o único objeto da "ciência jurídica" e que não admite conexão entre o Direito, a moral e a política, servia

3 Para uma análise do "neoconstitucionalismo" como equivalente ao "pós-positivismo", pode-se consultar o pensamento de Manuel Atienza. ATIENZA, Manuel. Entrevista a Robert Alexy. Cuadernos de Filosofía del Derecho, n. 24, Alicante: Doxa, 2001, p. 672-73. Para um estudo aprofundado do "neoconstitucionalismo" em suas mais diversas vertentes teóricas, consultar: CARBONELL, Miguel (Coord.). Neoconstitucionalismo(s). 2. ed. Madrid: Trotta, 2005; CARBONELL, Miguel (Coord.). Teoría del neoconstitucionalismo: ensaios escogidos. Madrid: trotta, 2007; SARMENTO, Daniel. O neoconstitucionalismo no Brasil: riscos e possibilidades. In: LEITE, George Salomão; SARLET, Ingo Wolfgang (Org.). Direitos Fundamentais e Estado Constitucional: estudos em homenagem a J. J. Gomes Canotilho. São Paulo; Coimbra: Revista dos Tribunais; Coimbra Editora, 2009, p. 09-49. 
a um modelo de sociedade, o modelo liberal-individualista. Em uma sociedade marcada pela homogeneidade política e igualdade formal jurídica, o sistema normativo que melhor garante a propriedade e a liberdade de mercado é, por certo, o sistema de regras.

Com a mudança no cenário social, a consolidação dos movimentos de classe, o fortalecimento de novos atores sociais, o pluralismo político e jurídico, a heterogeneidade política da sociedade, evidencia-se a necessidade de repensar as bases teóricas do Direito. Neste sentido, fala-se em pós-positivismo, aqui entendido como a teoria contemporânea que procura enfrentar os problemas da indeterminação do Direito e sustenta a situação de estreita relação entre Direito, moral e política ${ }^{4}$.

No Estado liberal ou "Estado de direito legislativo", como se refere Gustavo ZAGREBELSKI, o legislador figura como o "senhor do direito", sendo visível uma total confusão entre lei e Direito. O Direito é o que está na lei e a justiça é o que a lei determina. Assim, o conceito de justiça importa à ordem moral e não à ordem jurídica (ZAGREBELSKI, 1995, p. 21-23). A jurisdição é pautada pela previsibilidade e segurança de um sistema fechado de regras jurídicas, que garante a propriedade privada e a liberdade de mercado para uma sociedade politicamente homogênea, típica do liberalismo clássico 5 .

O modelo liberal de Estado de direito, muito embora garanta aos indivíduos um considerável nível de segurança jurídica (sistema de regras jurídicas), padece de um insuprimível déficit de legitimidade, resultado de seu sensível afastamento das preocupações com os postulados da justiça material e da

\footnotetext{
4 Para o estudo mais aprofundado do pós-positivismo, pode-se consultar: CALSAMIGLIA, Albert. Postpositivismo. Cuadernos de Filosofía del Derecho, n. 21-I, Alicante: Doxa, 1998. No Brasil, o termo "pós-positivismo" é usado com forte semelhança de sentido, entre outros, por Paulo BONAVIDES. BONAVIDES, Paulo. Curso de Direito Constitucional. 10. ed. São Paulo: Malheiros, 2000, p. 228-66. Para o estudo das idéias que marcam o chamado pluralismo jurídico, aqui referido, consultar: WOLKMER, Antonio Carlos. Pluralismo Jurídico: fundamentos de uma nova cultura no direito. 3. ed. São Paulo: Alfa Ômega, 2001.

5 Para a análise das bases teóricas do liberalismo clássico, consultar: LOCKE, John. Dois tratados sobre o governo. Tradução de Júlio Fischer. São Paulo: Martins Fontes, 1998.
} 
igualdade substancial. A postura teórica de relegar as preocupações com os ideais de justiça e igualdade para a ordem moral, típica do positivismo jurídico, acaba por distanciar o Direito de uma de suas funções primordiais: a consecução da justiça.

De forma diversa, o neoconstitucionalismo caracteriza-se pela prevalência da Constituição. $\mathrm{O}$ dogma da sujeição à lei é substituído pela máxima da sujeição à Constituição, enquanto sistema normativo aberto constituído por regras e princípios voltados à consecução da justiça material. A figura do legislador como "senhor do direito", traço característico do Estado liberal, é superada pelo agigantamento da importância dos juízes, não como novos "senhores do direito", situação incompatível com a própria idéia contemporânea de constitucionalismo, mas enquanto importantes atores no processo de efetivação e concretização dos direitos fundamentais (ZAGREBELSKI, 1995, p. 150-53).

Nada obstante, não se pode olvidar que o neoconstitucionalismo não deve ser encarado como uma proposta acabada de teoria do direito, com pretensões de sistematicidade e adequação. $\mathrm{Na}$ verdade, sob o rótulo ainda em construção do neoconstitucionalismo, reúnem-se diversas doutrinas de teoria constitucional, por vezes até entre si contraditórias. Umas mais radicais e inconciliáveis até com os mais abertos modelos de "positivismo jurídico crítico" 6 , outras, porém, em certa medida conciliáveis com esses últimos. Por outro lado, em maior ou menor amplitude, todas essas doutrinas estão voltadas à consolidação de uma sólida teoria da supremacia da Constituição,

6 No que toca ao positivismo jurídico crítico, pode-se estudar a teoria do garantismo jurídico do jurista italiano Luigi FERRAJOLI, que oferece um sofisticado modelo de positivismo jurídico crítico, a partir da sólida limitação dos poderes públicos constituídos (Estado de direito) e efetiva defesa dos direitos fundamentais, mas sem incorrer nos déficits de legitimidade e indeterminação do ativismo judicial ponderacionista (argumentação de princípios). Para o estudo do garantismo jurídico: CARBONELL, Miguel; SALAZAR, Pedro (Coord.). Garantismo: estudios sobre el pensamiento jurídico de Luigi Ferrajoli. Madrid: Trotta, 2005; CADEMARTORI, Sérgio. Estado de direito e legitimidade: uma abordagem garantista. 2. ed. Campinas (SP): Millennium, 2007; FERRAJOLI, Luigi. Garantismo: una discusión sobre derecho y democracia. Madrid: Trotta, 2006; FERRAJOLI, Luigi. Derecho y razón: teoría del garantismo penal. 4. ed. Madrid: Trotta, 2000; FERRAJOLI, Luigi. Principia iuris: teoria del diritto e della democrazia. Roma: Laterza, 2007. 
da defesa da força normativa dos princípios constitucionais, da eficácia dos direitos fundamentais, da interpretação conforme a Constituição e do reconhecimento do Judiciário como instância de concretização dos direitos fundamentais?

Nessa marcha histórico-evolutiva do pensamento jurídico-político, atualmente os princípios constitucionais constituem-se em normas que fundamentam e sustentam o sistema, as pautas supremas e basilares do ordenamento jurídico de uma dada sociedade. Não são meros programas ou linhas sugestivas às ações do Poder Público ou dos cidadãos, mas sim as vinculam e direcionam, porquanto dotados de eficácia jurídica vinculante.

Os princípios constitucionais funcionam como verdadeiros veículos de justiciabilidade do Direito, na medida em que fomentam o cultivo do sistema jurídico pelas fecundas sementes do discurso prático, da argumentação moral, reinserindo no centro do Direito as preocupações com a satisfação da justiça material. É pela via dos princípios jurídicos que as pautas morais informadoras do discurso prático invadem o ordenamento jurídico, vinculando o Direito a uma inafastável e indubitável preocupação com a justiça material, um fator de considerável mitigação daquele insuprimível déficit de legitimidade, marca indelével do Estado liberal de direito pautado pelo positivismo jurídico.

\section{O CONCEITO DE PRINCÍPIOS CONSTITUCIONAIS E A DISTINÇÃO ESTRUTURAL ENTRE REGRAS E PRINCÍPIOS JURÍDICOS}

O conceito de princípios constitucionais passa pela noção de sistema jurídico ${ }^{8}$, que se constitui no pilar estruturante da metodologia jurídica contemporânea, servindo de sustentá-

7 Para uma análise sobre a problemática da eficácia dos direitos fundamentais, consultar: SARLET, Ingo Wolfgang. A eficácia dos Direitos Fundamentais. 4. ed. Porto Alegre: Livraria do Advogado, 2004.

80 estudo mais aprofundado do conceito de sistema jurídico já foi empreendido alhures: CRISTÓVAM, José Sérgio da Silva. Colisões entre princípios constitucionais: razoabilidade, proporcionalidade e argumentação jurídica. 1. ed. 4. tir. Curitiba: Juruá, 2011, p. 39-63. 
culo e base conformadora ao neoconstitucionalismo. Sistema jurídico, entendido como um conjunto de regras e princípios jurídicos que orientam determinado espaço territorial, em um dado momento histórico.

A consolidação do neoconstitucionalismo possibilitou a sedimentação da teoria da normatividade dos princípios jurídicos. Sob as bases do neoconstitucionalismo, aqueles princípios gerais de Direito, destituídos de força normativa tanto no jusnaturalismo como no positivismo jurídico, correspondem aos princípios constitucionais, espécies normativas dotadas de substancialidade e aplicabilidade. A idéia de princípios constitucionais está intimamente ligada à noção de fundamento, base, pressuposto teórico que orienta e confere coerência a todo o arcabouço lógico e teleológico do sistema jurídico constitucional.

Os princípios constitucionais são normas que sustentam todo o ordenamento jurídico, tendo por função principal conferir racionalidade sistêmica e integralidade ao ordenamento constitucional. Podem ser expressos mediante enunciados normativos ou figurar implicitamente no texto constitucional. Constituem-se em orientações e mandamentos de natureza informadora da racionalidade do ordenamento e capazes de evidenciar a ordem jurídico-constitucional vigente. Não servem apenas de esteio estruturante e organizador da Constituição, representando normas constitucionais de eficácia vinculante na proteção e garantia dos direitos fundamentais 9 .

A análise dos princípios jurídicos pode ser conduzida tanto sob o prisma funcional como o estrutura ${ }^{10}$. O debate acerca

\footnotetext{
$9 \mathrm{Na}$ doutrina nacional, para uma crítica bastante abalizada à teoria dos princípios constitucionais, sob os parâmetros do modelo teórico do neoconstitucionalismo, pode-se consultar os estudos de Lenio Luiz STRECK e a sua crítica ao que passou a chamar de "panprincipiologismo", sobretudo no que toca ao problema da discricionariedade judicial na solução dos chamados "casos difíceis". STRECK, Lenio Luiz. Verdade e consenso. 4 ed. São Paulo: Saraiva, 2011.

10 Para estudos complementares acerca da distinção entre regras e princípios jurídicos, pode-se consultar a análise empreendida por Humberto ÁVILA, quando apresenta ainda o conceito de postulados normativos enquanto metanormas que se constituem em deveres situados em um segundo grau e estabelecem a es-
} 
das funções dos princípios constitucionais será empreendido mais adiante, restando por hora o enfrentamento da temática referente à pretensa diferenciação estrutural ou morfológica das normas jurídicas em regras e princípios.

Essa concepção estrutural dos princípios constitucionais e a conformação das regras e princípios enquanto espécies normativas distintas, segundo Robert ALEXY, constitui "o marco de uma teoria normativo-material dos direitos fundamentais e, com isso, um ponto de partida para responder à pergunta acerca da possibilidade e dos limites da racionalidade no âmbito dos direitos fundamentais" (ALEXY, 1993, p. 81-82).

A distinção das normas em regra e princípios jurídicos pode ser encarada como um dos pilares essenciais do edifício da teoria dos direitos fundamentais. No mesmo sentido, a consolidação da idéia de normatividade dos princípios jurídicos se converte em elemento significativo para uma segura e salutar transposição da teoria formal-positivista, avançando-se para o estabelecimento de uma teoria material da Constituição e dos princípios constitucionais. Resta oportuno examinar se a mencionada distinção forte ou lógica entre regras e princípios jurídicos vem sustentada por uma adequada teoria justificadora.

Sustenta ALEXY que regras e princípios são normas jurídicas, porquanto ambos se formulam com a ajuda das expressões deônticas fundamentais, como o mandamento, a permissão e a proibição. Assim, as regras e os princípios jurídicos são espécies de normas que se constituem em fundamentos para juízos concretos de "dever ser" (ALEXY, 1993, p. 83).

Um primeiro traço característico que pode ser tomado em conta na distinção entre regras e princípios jurídicos é a característica da fundamentalidade. Por este critério, os princípios são qualificados como as normas fundamentais do sistema jurídico, o fundamento jurídico-político de todo o ordenamento. Os

trutura de aplicação dos princípios e das regras. ÁVILA, Humberto. Teoria dos princípios: da definição à aplicação dos princípios jurídicos. 4. ed. São Paulo: Malheiros, 2004, p. 21-86. 
princípios constituem-se nas decisões básicas e nucleares informadoras de todo o sistema, inspirando e dotando de unidade e adequação valorativa o ordenamento jurídico.

Muito embora a fundamentalidade se constitua em traço que inegavelmente sustenta certa distinção entre regras e princípios jurídicos, Luis PRIETO SANCHÍS afasta sua utilidade como critério distintivo, sob o argumento de que as disposições fundamentais podem adotar qualquer estrutura e não, necessariamente, a forma de princípios jurídicos. Ademais, os princípios não são obrigatoriamente veiculados por meio das fontes superiores ou constitucionais, podendo até assumir um caráter implícito. Não se quer, contudo, afastar a idéia de fundamentalidade dos princípios jurídicos, apenas reconhecer sua debilidade como traço distintivo com relação às regras jurídicas (PRIETO SANCHÍS, 1992, p. 58-59).

Os critérios de distinção entre regras e princípios são consideravelmente numerosos, cabendo grande ênfase ao "critério de generalidade", que defende os princípios como normas de um grau de abstração relativamente alto, enquanto as regras ostentam um nível de abstração relativamente baixo ${ }^{11}$.

Há que se distinguir, primeiramente, os conceitos de generalidade e universalidade das normas jurídicas. A universalidade de uma norma não depende de sua maior ou menor generalidade, exigindo apenas que a norma seja direcionada a todos os indivíduos de uma classe aberta. Neste sentido, a idéia de

11 Existem, ainda, vários outros critérios como o que discute a "determinabilidade dos casos de aplicação", sob o argumento de que os princípios, por serem vagos e indeterminados, necessitam de mediações concretizadoras, ao passo que as regras comportam aplicação direta; o da "diferenciação entre normas criadas e normas crescidas"; o da "explicitação do conteúdo valorativo"; o da "proximidade da idéia de direito", pelo qual os princípios são "standards" juridicamente vinculantes fundados nas exigências de justiça ou na idéia de direito, ao passo que as regras podem ser normas dotadas de conteúdo meramente funcional; e, para finalizar, o critério da "importância que têm para o ordenamento normativo". Neste sentido, consultar: ALEXY, Robert. Teoría de los derechos fundamentales. Traducción de Ernesto Garzón Valdés. Madrid: Centro de Estudios Constitucionales, 1993, p. 83-84; BONAVIDES, 2000, p. 248-50; e, CANOTILHO, José Joaquim Gomes. Direito Constitucional e teoria da Constituição. 7. ed. Coimbra: Almedina, 2003, p. $1159-64$. 
universalidade se opõe à individualidade, enquanto o conceito de generalidade resta oponível à noção de especialidade. Uma norma jurídica é sempre ou bem universal ou individual, ao passo que sua generalidade ou especialidade se configura em uma questão de grau (ALEXY, 1993, p. 83-84).

A partir de uma caracterização linguística, procura-se estabelecer os traços distintivos de generalidade e vagueza dos princípios frente às regras jurídicas. Não se pode olvidar que estes traços distintivos se constituem em "propriedades graduais que não permitem definir categorias fechadas, mas tão-somente ordenar os diversos produtos normativos em uma ampla escala de generalidade e vagueza" (PRIETO SANCHÍS, 1992, p. 60).

$\mathrm{O}$ atributo da generalidade pode tanto estar vinculado ao número de sujeitos submetidos a determinado enunciado normativo como ao número de situações ligadas a certa consequência jurídica. Desta forma, a generalidade não se apresenta como um eficaz critério distintivo entre princípios e regras jurídicas, porquanto as regras também podem ser aplicadas a um número indeterminado de sujeitos e atos ou fatos jurídicos.

Não se pode negar, por outro lado, que embora as regras possam ser estabelecidas para um número indeterminado de atos ou fatos jurídicos, vinculando a ação de uma universalidade de sujeitos, são marcadas pelo traço da especialidade, no sentido de que não regulam senão aquelas situações jurídicas determinadas. Em contrapartida, os princípios são gerais na medida em que admitem um leque infinito de aplicações.

A questão referente à vagueza da linguagem normativa representa o que se pode chamar de "insuprimível margem de indeterminação semântica”. Esta margem de indeterminação semântica "tanto pode afetar a extensão do enunciado, isto é, os objetos compreendidos dentro do mesmo (denotação) como a sua intensidade ou propriedades caracterizadoras de tais objetos (conotação)" (PRIETO SANCHÍS, 1992, p. 61).

A vagueza das normas jurídicas surge quando não se pode precisar se determinado caso concreto está ou não regulado 
pela disposição normativa, dada a abertura ${ }^{12}$ e indeterminação semântica do suposto abstrato previsto na norma. Ocorre que os atributos de abertura e indeterminação semântica, embora comuns aos princípios jurídicos, também podem ocorrer nas regras jurídicas, o que afasta o critério linguístico como traço distintivo decisivo entre regras e princípios jurídicos, forçando admitir que os critérios tradicionais não conseguem respaldar uma diferenciação estrutural forte entre regras e princípios jurídicos.

Embora não se tenha, até o presente momento, alcançado parâmetros irrefutáveis sob os quais seja possível respaldar uma distinção estrutural forte entre regras e princípios jurídicos, mostra-se em tudo oportuno aprofundar a análise do pensamento jurídico de dois dos mais importantes e influentes autores contemporâneos que se ocuparam da presente temática.

\section{NORMAS, PRINCÍPIOS E DIRETRIZES NA FILOSOFIA JURÍDICA DE RONALD DWORKIN}

Desde quando começou a ser apresentada sua filosofia jurídica, na década de 1970, Ronald DWORKIN segue reconhecido como o maior e mais implacável crítico do positivismo jurídico. Inegavelmente, seu pensamento constitui-se na mais difundida e inquietante crítica sistematizada às bases teóricas e filosóficas das concepções juspositivistas, o que desencadeou forte reação dos seus defensores, propiciando um fecundo momento de debate para a teoria e a filosofia do Direito.

Partindo da filosofia de John RAWLS, sobretudo o conceito de posição original e os dois princípios de justiça, a liberdade e a igualdade, que seriam aqueles eleitos pela comuni-

12 Conforme sustenta Herbert L. A. HART, independentemente do "processo escoIhido, precedente ou legislação, para a comunicação de padrões de comportamento, estes, não obstante a facilidade com que actuam sobre a grande massa de casos correntes, revelar-se-ão como indeterminados em certo ponto em que a sua aplicação esteja em questão; possuirão aquilo que foi designado como textura aberta". HART, Herbert L. A. O conceito de Direito. Tradução de Armindo Ribeiro Mendes. 2. ed. Lisboa: Fundação Calouste Gulbenkian, 1996, p. 140-41. 
dade na posição original (RAWLS, 1997), DWORKIN pretende construir uma teoria geral do Direito que não exclua nem o raciocínio moral nem o raciocínio filosófico, em um modelo baseado nos princípios do liberalismo individualista. Segundo sustenta Albert CALSAMIGLIA, a filosofia jurídica dworkiniana deve ser encarada como um interessante ponto de partida tanto à crítica do positivismo jurídico como da filosofia utilitarista $^{13}$, sendo que a sua pretensão consiste em fundamentar uma filosofia política liberal sobre bases mais sólidas, progressistas e igualitárias (CALSAMIGLIA, In. DWORKIN, 1989, p. 07).

No ataque às teses juspositivistas, tomando como ponto de referência o modelo hartiano, considerada a mais depurada versão do positivismo jurídico, DWORKIN rechaça a separação entre Direito e moral ${ }^{14}$, o modelo de Direito enquanto sistema de regras, a tese da discricionariedade judicial e da impossibilidade de única resposta correta para todos os casos, defendendo a unicidade de solução justa principalmente para os chamados casos difíceis.

13 Discutindo acerca das bases de sua teoria, chamada de teoria liberal do Direito, DWORKIN delimita claramente o objeto de sua crítica, referindo-se a uma teoria que em geral se considera liberal, designada como teoria jurídica dominante e composta de duas partes independentes: "A primeira é uma teoria acerca do que é o Direito; dito informalmente, trata-se de uma teoria sobre as condições necessárias e suficientes para que uma proposição jurídica seja válida. Esta é a teoria do positivismo jurídico, que sustenta que a verdade das proposições jurídicas consiste em fatos que fazem referência às regras que têm sido adotadas por instituições sociais específicas, e nada mais. A segunda é uma teoria sobre o que deve ser o Direito e sobre como devem ser as instituições jurídicas conhecidas. Tal é a teoria do utilitarismo, que sustenta que o Direito e suas instituições deve servir ao bem-estar geral e nada mais. Ambas as partes da teoria dominante derivam da filosofia de Jeremy Bentham". DWORKIN, Ronald. Los derechos en serio. Traducción de Marta Guastavino. 2. ed. Barcelona: Ariel Derecho, 1989, p. 31.

$14 \mathrm{O}$ estudo mais aprofundado acerca da relação de entrelaçamento e complementaridade entre Direito e moral, pode ser feito a partir dos escritos de Jurgen HABERMAS. Em um primeiro momento, o autor procura explicar como o Direito positivo, com a ajuda do Direito natural racional, evoluiu para a diferenciação do complexo tradicional formado pela moral, o Direito e a política. Em seguida, partindo da relação entre o Direito natural racional e a moderna concepção de Estado de direito, HABERMAS discute, baseado em uma perspectiva interna, a relação de complementaridade entre Direito e moral. HABERMAS, Jurgen. ¿Como es posible la legitimidad por vía de legalidad? Traducción de Manuel Jiménez Redondo. Cuadernos de Filosofía del Derecho, n. 05, Alicante: Doxa, 1988, p. 21-45. 
A filosofia jurídica dworkiniana está fundada em uma forte teoria dos direitos, que encara os direitos individuais, sobretudo o direito à igual consideração e respeito, como verdadeiros trunfos frente à maioria. Uma teoria individualista e antiutilitarista que não admite a superioridade das diretrizes políticas ou objetivos sociais frente a um autêntico direito. $\mathrm{O}$ utilitarismo, enquanto teoria que justifica a subordinação dos direitos individuais a finalidades coletivas e objetivos sociais, posiciona-se em sentido contraposto a uma autêntica teoria dos direitos, uma vez que "os objetivos sociais somente são legítimos quando respeitam os direitos dos indivíduos. Uma verdadeira teoria dos direitos deve dar prioridade aos direitos frente aos objetivos sociais" (CALSAMIGLIA, In. DWORKIN, 1989, p. 17).

Uma das teses centrais à filosofia jurídica de DWORKIN é a fusão entre Direito e moral, com a qual o autor ataca frontalmente as bases do juspositivismo.

Esses modelos juspositivistas não ignoram que por trás de cada norma ou disposição jurídica se encontra uma opção moral ou política, nem que existe uma filosofia política anteposta à Constituição e que as decisões judiciais albergam princípios morais. O que ambos defendem é a possibilidade e a necessidade de separação entre as dimensões jurídica e moral. Para ser mais exato, sustentam que as disposições normativas não encontram seu pressuposto de validade em nenhuma filosofia política ou discurso moral, mas sim em outras disposições normativas reconhecidamente válidas, conforme previsto por uma norma hierarquicamente superior, a exemplo da norma fundamental ou da regra de reconhecimento.

DWORKIN, por outro lado, afirma a inteira fusão entre Direito e moral a partir de uma teoria forte dos princípios, baseada na existência de uma distinção lógica entre regras e princípios, muito embora essa distinção não seja enfaticamente levada para o âmbito da aplicação do Direito, o que fica claro quando o autor suscita que quando se propõe uma solução para casos difíceis, pode-se também alcançar os casos fáceis. 
Discutindo acerca da regra de reconhecimento de HART e a partir do critério do apoio institucional, que pressupõe um procedimento empírico para a determinação da relevância jurídica de um princípio, DWORKIN propõe o seguinte critério de identificação do Direito: "um princípio é um princípio de direito se figura na teoria do direito mais lógica e melhor fundamentada que se possa apresentar como justificação das normas institucionais e substantivas explícitas da jurisdição em questão" (DWORKIN, 1989, p. 128).

Neste sentido, sendo admissivel que uma teoria do Direito deva proporcionar uma base para o dever judicial, "então os princípios que enuncia devem justificar as normas estabelecidas, identificando as preocupações e tradições morais da comunidade que, na opinião do jurista que elaborou a teoria, fundamentam realmente as normas" (DWORKIN, 1989, p. 129).

Sobre a relação de justaposição entre Direito e moral na teoria jurídico-filosófica dworkiniana, PRIETO SANCHÍS afirma que a moral penetra no mundo do Direito por meio de um "procedimento um tanto misterioso que dá lugar a uma normatividade um tanto indiferenciada, onde princípios morais e regras jurídicas parecem constituir um sistema coerente do ponto de vista material ou valorativo". Assim, a moral não deve ser vista como um ordenamento de normatividade apartado do Direito, que o influencia apenas pelas vias institucionalizadas do legislador, do juiz e etc. O discurso moral se apresenta justaposto ao jurídico, de forma que toda decisão jurídica encontra substrato em uma argumentação moral e toda regra institucional está ligada a um princípio moral (PRIETO SANCHÍS, 1992, p. 79).

Quando os princípios morais subscritos pelo juiz para justificar as normas explícitas são bons e justos, significa que o Direito em questão resulta moralmente aceitável. Se, por outro lado, estes princípios bons e justos não fazem parte da teoria do Direito mais forte, porque as normas explícitas são tão injustas que não podem ser justificadas mediante tais princípios, e mesmo assim são aplicadas pelos juízes, há que se admitir que os 
princípios podem ser imorais e também que o sistema jurídico vigente pode ser injusto.

Segundo se extrai da teoria dworkiniana, os princípios jurídicos valem enquanto tal porque se constituem em princípios morais que justificam o ordenamento jurídico; porque são princípios morais bons e justos que se mostram coerentes com um sistema jurídico basicamente justo. Portanto, muito embora seja possível a identificação dos princípios jurídicos válidos do sistema por meio de uma regra de reconhecimento típica do modelo hartiano, há uma sensível diferença funcional que torna incompatível tal expediente: enquanto a regra de reconhecimento serve para descrever o direito vigente e atestar a validade de práticas sociais específicas, segundo uma proposta teórica moralmente neutra e desvencilhada de propósitos de justificação ${ }^{15}$, os princípios desenvolvidos por DWORKIN servem para justificar a existência de certos deveres jurídicos baseados na existência de regras morais, uma justaposição entre Direito e moral que permite um redimensionamento do conceito de Direito (PRIETO SANCHÍS, 1992, p. 82-86).

A concepção dworkiniana de Direito e sua justaposição com a moral está baseado em uma teoria forte dos princípios, o que resulta na defesa de uma distinção lógica ou estrita entre princípios e regras jurídicas. Após apresentar em linhas gerais o cerne das concepções positivistas e o edifício teórico que sustenta o conceito de Direito em HART, o chamado modelo de regras, DWORKIN inicia seu "ataque geral contra o positivismo”, partindo da distinção entre normas (regras) ${ }^{16}$, princípios e diretrizes políticas.

$15 \mathrm{O}$ próprio HART admite textualmente que seu propósito consiste em oferecer uma teoria do que é o Direito do ponto de vista geral e descritivo: geral porque não se refere a nenhum sistema jurídico particular; descritivo porque se propõe moralmente neutra e desprovida de propósitos de justificação. RAMÓN DE PÁRAMO, Juan. Entrevista a H. L. A. Hart. Cuadernos de Filosofía del Derecho, n. 05, Alicante: Doxa, 1988, p. 348.

16 DWORKIN usa o termo norma como pauta diferente dos princípios em uma acepção genérica. Entretanto, o termo norma será substituído por regra, uma vez que norma tem sido aqui entendida como gênero dos quais figuram como espécies os princípios e as regras jurídicas. No mesmo sentido: ALEXY, 1993, p. 83; PRIETO SANCHÍS, 1992, p. 32. 
Em determinados problemas práticos, sobretudo naqueles casos difíceis, quando os profissionais do Direito discutem e arrazoam acerca de direitos e obrigações jurídicas, acabam fazendo uso de pautas (standards) que não desempenham suas funções enquanto regras, funcionando sim como princípios, diretrizes políticas (policies) e outros tipos de standards, que não são devidamente reconhecidos pelo positivismo jurídico (DWORKIN, 1989, p. 72).

A categoria dos princípios jurídicos pode aparecer na filosofia jurídica dworkiniana com sentidos diversos: em uma acepção genérica, com referência a todo o conjunto daqueles standards que não se constituem em regras; em um sentido mais preciso, quando o termo princípio resta distinto das diretrizes políticas. As diretrizes políticas, ou simplesmente diretrizes, são aquelas pautas que estabelecem objetivos a serem alcançados, no mais das vezes ligados a aspectos econômicos, políticos ou sociais da comunidade. Os princípios, por outro lado, são pautas que devem ser observadas porque correspondem a um imperativo de justiça, de equidade (fairness) ou outra dimensão da moral positiva, e não porque potencializam ou asseguram uma situação econômica, política ou social desejável.

Voltando à distinção lógica entre princípios e regras jurídicas, DWORKIN sustenta que as regras são aplicáveis à maneira de um "tudo ou nada" (all-or-nothing), ou são completamente aplicáveis ou não possuem nenhuma aplicação. Dito de outra forma, atestado que determinada questão prática atende aos pressupostos fáticos hipoteticamente previstos pela regra, sendo a mesma válida, deve ser aplicada com todas as suas consequências jurídicas. Os princípios, por outro lado, constituem-se em razões para decidir, não sendo aplicáveis automaticamente quando satisfeitas as condições previstas como suficientes a sua aplicação, característica que os confere a qualidade de critérios que devem ser levados em conta quando da decisão judicial (DWORKIN, 1989, p. 75-76). 
Segundo expõe PRIETO SANCHÍS, a caracterização defendida por DWORKIN pode ser assimilada de duas maneiras distintas. Primeiramente, pode-se entender que, enquanto as regras são sempre aplicáveis à maneira de um "tudo ou nada", os princípios estão limitados a orientar uma interpretação normativa duvidosa, jamais oferecendo a solução ao problema prático e sim norteando a interpretação de outras regras mais conclusivas. Assim, os princípios não possibilitariam uma resposta categórica, mas simplesmente controlariam as soluções possivelmente dedutíveis a partir do conjunto das regras (PRIETO SANCHÍS, 1992, p. 33-34). Embora possa parecer uma interpretação até certo ponto aceitável da teoria de DWORKIN, deve-se rechaçá-la não só por ser destoante dos modelos de Direito positivo contemporâneo, mas principalmente por se afastar da sua proposta teórica.

Outra forma de interpretar a distinção lógica proposta por DWORKIN não leva em conta que, quando da aplicação no caso concreto, as regras são conclusivas e os princípios não, mas sim que a priori é possível discernir com precisão os casos que impõem seja observada uma regra, porquanto o ordenamento prevê todas as possíveis exceções a sua aplicação, ao passo que os princípios não podem dispor de uma cláusula desse gênero. Não se pode precisar ou catalogar as situações em que tem aplicação determinado princípio, muito menos a sua intensidade e influência na solução do caso concreto (PRIETO SANCHÍS, 1992, p. 35-36).

Em sentido bastante semelhante, Manuel ATIENZA e Juan RUIZ MANERO defendem que os princípios em sentido estrito configuram o caso de forma aberta, enquanto as regras de forma fechada. Enquanto nas regras as propriedades que conformam o caso constituem um conjunto fechado, resta impossível a formulação de uma lista completa das propriedades que constituem as condições de aplicação para os princípios. Não se trata apenas de maior ou menor espaço de vagueza, mas sim de diferentes tipos de indeterminação que afetam aos princípios e às regras 
jurídicas, ainda que entre as duas espécies normativas possam existir zonas de penumbra (ATIENZA; RUIZ MANERO, 1991, p. 108).

Partindo da primeira qualidade distintiva que defende a aplicação das regras à maneira de um "tudo ou nada" e dos princípios enquanto razões para decidir, DWORKIN sustenta outro traço distintivo caracterizado pela dimensão do peso ou importância, típica dos princípios. Quando para a resolução de determinado problema uma pluralidade de princípios se coloca em posição de conflito, há que se considerar o peso relativo de cada um deles, conferindo-se prevalência ao que apresentar maior densidade, o que não enseja a invalidação dos demais. As regras, por outro lado, não possuem a dimensão do peso ou importância e quando postas em conflito, da aplicação de uma decorre necessariamente a invalidação das demais a ela contrapostas. Os critérios para a invalidação das regras jurídicas podem variar dependendo de cada ordenamento jurídico ${ }^{17}$, podendo ser conferida prevalência à regra hierarquicamente superior, a mais recente, a mais específica ou à fundada nos princípios mais importantes (DWORKIN, 1989, p. 77-78).

Certamente, a valoração acerca do maior peso ou importância de determinado princípio em contradição com outras pautas, todos explícita ou implicitamente reconhecidos pelo ordenamento jurídico, é evidentemente inexata e amplamente controvertida. Nada obstante, DWORKIN sustenta que as discussões acerca da dimensão do peso ou importância de cada princípio integram a própria essência do conceito de princípio.

A este traço distintivo PRIETO SANCHÍS apresenta algumas oposições. Argumenta que não fica muito claro se o peso dos princípios deve ser decidido em abstrato, mediante algum critério de ordenação hierárquica, ou deve levar em conta as circunstâncias do caso concreto. Sustenta, ainda, a possibilidade de uma antinomia total entre dois princípios, o

17 O estudo acerca dos critérios para a resolução das antinomias jurídicas já foi realizado alhures: CRISTÓVAM, 2011, p. 222-230. 
que exigiria a invalidação de uma deles, à semelhança do que ocorre no conflito entre regras (PRIETO SANCHÍS, 1992, p. 40-41).

Essas críticas não conseguem invalidar as proposições dworkinianas. Ao que parece, DWORKIN defende algo aproximado à relação de precedência condicionada sustentada por ALEXY, afastando a idéia de uma ordenação hierárquica abstrata pré-estabelecida que fatalmente engessaria a dinamicidade própria dos princípios. Quanto à possibilidade de antinomia total entre princípios, o que exigiria a invalidação de umas das pautas, ainda que teoricamente possível, esse argumento não tem o condão de afastar a densidade como critério distintivo entre regras e princípios.

Outra crítica mais consistente levada a efeito por PRIETO SANCHÍS parte da seguinte indagação: se as regras não dispõem da propriedade do peso ou importância, no caso de conflito uma deve ser necessariamente declarada inválida ou resta tão-somente vedada a aplicação de ambas ao mesmo tempo? Aceitando-se a primeira assertiva, coerente com a teoria de DWORKIN, não se poderia tomar a propriedade do peso como critério distintivo entre regras e princípios, uma vez que em tese estes também são passíveis de invalidação. A segunda hipótese é muito mais corrente naqueles ordenamentos em que vigora o critério da conservação das normas. Por este parâmetro pretende-se estabelecer distinções parciais nos âmbitos de aplicação das regras com sentidos deônticos contraditórios, dissolvendo a contradição a partir de um critério de especialidade ou de uma cláusula de exceção, o que se aproxima muito da dimensão do peso ou importância defendida como traço típico dos princípios (PRIETO SANCHÍS, 1992, p. 42-43).

Não se pode desconsiderar que a teoria forte dos princípios defendida por DWORKIN abre caminho para críticas consistentes, fundadas em argumentos capazes de por em dúvida a pretensa distinção lógica ou estrutural entre regras e princípios jurídicos. O próprio autor admite textualmente que a forma de 
um standard nem sempre deixa estreme sua qualidade de princípio ou regra jurídica, havendo casos em que ambos podem desempenhar funções muito semelhantes, quando a distinção acaba se consubstanciando quase que exclusivamente em uma questão de forma (DWORKIN, 1989, p. 78-79).

\section{OS PRINCÍPIOS JURÍDICOS NO PENSAMENTO DE ROBERT ALEXY}

Juntamente com o pensamento dworkiniano, a teoria jurídica de ALEXY se apresenta como uma das mais influentes dentro do modelo pós-positivista, que tem marcado o novo constitucionalismo. Conforme restará evidenciado, embora a teoria do Direito desenvolvida por ALEXY apresente inegáveis pontos de semelhança e aproximação com a obra de DWORKIN, inclusive no âmbito da divisão do sistema jurídico em regras e princípios, ambas expressam tanto diferenças formais como substanciais (ATIENZA, 2001, p. 674).

ALEXY assenta grande parte de sua teoria dos direitos fundamentais na divisão estrutural entre regras e princípios jurídicos como espécies normativas distintas. Segundo o autor, as regras são normas que se constituem em mandamentos definitivos, sendo que os direitos baseados em regras são direitos definitivos. Diversamente, os princípios são normas que ordenam que algo deva ser feito na maior medida fática e juridicamente possível. Estando as possibilidades jurídicas determinadas por regras e por outros princípios opostos, há exigência de ponderação, sendo que os direitos baseados em princípios não são definitivos e sim prima facie (ALEXY, 1994, p. 40-41).

A distinção entre regras e princípios jurídicos proposta por ALEXY abandona o âmbito gradual e avança para aspectos qualitativos. Para o autor, os princípios são normas que ordenam a realização de determinado direito na maior medida possível, dentro das possibilidades jurídicas e reais existentes, enquanto as regras somente podem ser cumpridas ou não. Se uma regra é 
válida, deve ser cumprida na sua exata medida, nem mais nem menos. As regras contêm determinações no âmbito do fático e juridicamente possível, ao passo que os princípios são "mandamentos de otimização" (ALEXY, 1993, p. 86-87).

Afirmar que a medida do cumprimento dos princípios está vinculada às possibilidades jurídicas significa dizer que a aplicação de determinado princípio depende diretamente dos princípios e regras jurídicas àquele contrapostos. Da mesma forma, a vinculação às possibilidades fáticas atesta que o conteúdo dos princípios somente pode ser determinado a partir do problema prático. Assim, pode-se dizer que os princípios veiculam obrigações prima facie, que podem ser derrogadas por outros princípios em caso de colisão, ao passo que as regras instituem obrigações absolutas, que não podem ser superadas por outras regras, devendo ser cumpridas na sua exata medida.

Pode-se dizer que a distinção entre regras e princípios jurídicos se apresenta como qualitativa ou conceitual. Neste caso, da mesma forma que DWORKIN, ALEXY rechaça a teoria segundo a qual entre regras e princípios há apenas uma diferenciação gradual, o que equivaleria admitir que os princípios nada mais são que regras com um alto nível de generalidade (LARRAÑAGA, 1994, p. 221).

O critério gradualista-qualitativo ${ }^{18}$ defendido por ALEXY consiste em conferir aos princípios o caráter jurídico de mandamentos de otimização, que podem ser cumpridos em diferentes graus, sendo que a medida devida de seu cumprimento depende não só das possibilidades reais, mas também das jurídicas.

Os princípios, normas impositivas de otimização, podem ser realizados ou concretizados em diferentes graus, variando segundo condições fáticas e jurídicas. $\mathrm{O}$ mesmo princípio pode apresentar variadas dimensões de aplicação na resolução de problemas práticos. $\mathrm{O}$ valor conferido a determinado princípio, em uma dada situação, poderá ser diverso em outra, podendo

18 Expressão empregada por Bonavides, a fim de identificar a tese defendida por ALEXY como apta a distinguir as duas espécies de normas jurídicas. BONAVIDES, 2000, p. 250. 
até, por vezes, ter sua aplicação afastada. Já as regras, normas que prescrevem uma dada situação ou impõem um determinado comportamento, quando válidas, devem ser cumpridas na exata medida de suas prescrições (ALEXY, 1988, p. 142-43).

Discutindo acerca das dimensões morais do Direito, Aleksander PECZENIK distingue regras e princípios de modo em tudo semelhante à teoria de ALEXY. Segundo PECZENIK, uma situação regulada por uma regra somente admite duas possibilidades, obedecê-la ou não. Assim, a ação humana pode ser qualificada como conforme ou contrária à determinada regra, em um caráter binário do tipo 0 ou 1 , tudo ou nada. Já os princípios estabelecem um ideal que se pode realizar em diferentes graus, sendo possível a qualificação de uma ação ou pessoa como mais ou menos perfeita à luz de determinados princípios, não no sentido binário e sim gradual (PECZENIK, 1990, p. 92).

Essa distinção estrutural fica clara quando da resolução das colisões entre princípios e dos conflitos entre regras, situações em que duas normas, aplicadas independentemente, conduzem a resultados incompatíveis, ou seja, a juízos de dever ser jurídico contraditórios ${ }^{19}$. Enquanto o conflito entre regras se resolve no plano da validade, com a invalidação de uma das regras em conflito ou a introdução de uma cláusula de exceção capaz de solucionar a contradição, a colisão entre princípios se resolve no plano do valor, tendo em vista as circunstâncias do caso, em uma relação de precedência condicionada (ALEXY, 1993, p. 87-92).

O conceito de princípios como mandamentos de otimização, como traço decisivo para respaldar a distinção entre regras e princípios, não está imune a críticas. Segundo defendem ATIENZA e RUIZ MANERO, nem todos os princípios podem ser cumpridos em diferentes graus, sendo esta qualidade afeta apenas aqueles princípios que estes autores definem como

19 Para um estudo acerca do conflito entre regras e da colisão entre princípios, bem como acerca da máxima da ponderação na teoria de ALEXY, consultar: CRISTÓVAM, 2011, p. 224-236. 
diretrizes, com a exclusão dos chamados princípios em sentido estrito $^{20}$.

Lançando objeções ao conceito de princípios de ALEXY, PRIETO SANCHÍS assevera que a hipótese de colisão total entre princípios, embora pouco corrente, não pode ser integralmente rechaçada. Da mesma forma, as características de mandamento de otimização e máxima da ponderação não cabem exclusivamente aos princípios, mas também para algumas regras que não se apresentam na forma binária, mas sim gradual. Neste sentido, a idéia de mandamento de otimização tem aplicação tanto para os princípios como para as regras, não servindo como critério decisivo de diferenciação. O mandamento de otimização representa antes uma técnica de argumentação, que pode ser útil na aplicação de qualquer standard normativo, e não um critério de diferenciação qualitativa entre regras e princípios. Em última análise, esta diferenciação normativa proposta por ALEXY com base na idéia de mandamento de otimização parece melhor caracterizar uma distinção funcional que morfológica ou estrutural (PRIETO SANCHÍS, 1992, p. 46-50).

O próprio ALEXY apresenta possíveis contestações ao conceito de princípios jurídicos enquanto mandamentos de otimização. A primeira se refere à possível existência de colisões de princípios solucionáveis mediante a declaração de invalidade, como ocorre no conflito entre regras. Entretanto, o autor admite esta possibilidade apenas no caso de princípios marcados por uma extremada debilidade, que não precedem a quaisquer outros em nenhum problema prático.

Outra possível oposição ao conceito de princípios como mandamentos de otimização remete à existência de princípios absolutos, sumamente fortes e capazes de preponderar em todos os casos de colisão. Há que se reconhecer, entretanto, que a

20 ATIENZA e RUIZ MANERO distinguem os princípios em sentido estrito - normas que expressam os valores superiores de um ordenamento jurídico, das diretrizes ou normas programáticas - normas que estipulam a obrigação de perseguir determinados fins. Apenas as diretrizes comportariam o cumprimento em diferentes graus, nos termos defendidos por ALEXY. ATIENZA e RUIZ MANERO, 1991, p. 105-10. 
existência de princípios absolutos é inconciliável com o próprio conceito de princípios defendido por ALEXY, porquanto estes não conheceriam limites jurídicos, mas tão somente fáticos. Ademais, esta idéia não se coaduna com a teoria dos direitos fundamentais, que exige estarem os princípios limitados por questões fáticas e jurídicas.

A última objeção que ALEXY enfrenta contra seu conceito de princípios jurídicos se refere à considerável amplitude desta concepção, englobando tanto os direitos individuais como os bens coletivos. Em decorrência de sua fragilidade, esta objeção é pouco combatida pelo autor, que se limita a demonstrar suas divergências com o conceito restritivo defendido por DWORKIN, para quem os princípios estariam adstritos aos direitos individuais, enquanto os bens coletivos seriam meras diretrizes políticas (PRIETO SANCHÍS, 1992, p. 109-111).

\section{PRINCÍPIOS CONSTITUCIONAIS E ARGUMENTAÇÃO JURÍDICA}

Além das funções apresentadas, cabe destacar a importância dos princípios no processo de justificação jurídica, o papel que desempenham na argumentação jurídica. Essa dimensão por assim dizer justificatória dos princípios jurídicos constitui-se em uma de suas mais relevantes funções dentro da teoria do Direito. Os princípios jurídicos não são apenas parâmetros explicativos do Direito, mas também e, sobretudo, pautas de justificação do discurso jurídico e da decisão judicial.

A dimensão justificatória dos princípios jurídicos é apresentada por ATIENZA e RUIZ MANERO, que sustentam ser próprio dos princípios o desempenho de duas funções básicas, uma função de explicação e outra de justificação. A função explicativa dos princípios jurídicos refere-se à capacidade destas normas em sintetizar os traços centrais do ordenamento, e dotá-lo de sentido e coerência. Afora a marcante qualidade sintetizadora, exsurge sua aplicação enquanto parâmetro de justifi- 
cação das decisões judiciais, como verdadeiras pautas de ponderação e conformação da argumentação jurídica (ATIENZA e RUIZ MANERO, 1991, p. 113-19).

Conforme defende PRIETO SANCHÍS, a utilização do modelo dos princípios como parâmetro de justificação das decisões judiciais, sobretudo quando da resolução dos chamados casos difíceis, deve ser analisada a partir de determinados métodos de interpretação, tais como o critério de universalização, as considerações consequencialistas e a interpretação sistemática (PRIETO SANCHÍS, 1992, p. 163).

\subsection{Argumentação de princípios e argumentação consequencialista}

Afora o critério de universalização, outro forte âmbito de justificação onde a teoria dos princípios desempenha um papel fecundo é a argumentação consequencialista. Consequencialismo aqui entendido como um modelo interpretativo informado pela argumentação teleológica ou finalista, segundo o qual "o ordenamento propõe certos valores ou objetivos políticos e morais que devem ser perseguidos por todos os operadores jurídicos" (PRIETO SANCHÍS, 1992, p. 170).

A grande restrição feita à aplicação da argumentação consequencialista sustenta sua contraposição à argumentação de princípios, porquanto esta consiste na adoção da melhor decisão baseada em critérios preexistentes e que devem ser aplicados independentemente dos seus resultados, ao passo que aquela é prospectiva e exige uma ponderação acerca dos benefícios políticos e sociais de determinada decisão para o futuro.

O caráter contraditório da relação entre estes dois âmbitos de argumentação é defendido por DWORKIN, quando distingue os princípios de justiça em sentido estrito e os princípios políticos, estes vinculados a questões marcadamente utilitárias de bem-estar social da maioria, comprometidos com o maior benefício possível ao maior número de cidadãos. Para DWORKIN, 
a argumentação consequencialista somente pode ser usada no processo de justificação da decisão judicial, após o esgotamento de todos os outros recursos de justificação, quando cabe ao julgador adotar a decisão que, segundo seu juízo, melhor satisfaça os objetivos do ordenamento jurídico.

Essas críticas à argumentação consequencialista são rechaçadas por PRIETO SANCHÍS, que nega sua contradição com a argumentação de princípios, até porque quando a interpretação é remetida àqueles argumentos não há simples alusão a concepções utilitárias - há sim preocupação com os resultados da decisão judicial, do ponto de vista dos princípios da liberdade das pessoas e do caráter democrático do Estado. No caso da eleição entre diversas interpretações deve-se decidir por aquela que possibilite maiores benefícios à satisfação de certo objetivo proposto pelo ordenamento jurídico ${ }^{21}$.

Circunscrito o consequencialismo fora do chamado "utilitarismo do ato" - a análise das consequências de uma decisão em um caso particular e sua avaliação do ponto de vista subjetivo do intérprete sobre o melhor resultado - e adstrito a um modelo de utilitarismo que examina os resultados da decisão sob uma perspectiva geral e conforme ao ordenamento jurídico, parece inegável a relevância da argumentação consequencialista (PRIETO SANCHÍS, 1992, p. 172-73). Se na decisão acerca de determinada situação, a norma prevista constitui uma das possíveis interpretações de alguma disposição jurídica válida, admitindo distintos graus de cumprimento, deve-se adotar aquela decisão que proporcione os melhores resultados, que melhor satisfaça os objetivos do ordenamento, o que implica em um cálculo consequencialista.

Não se pode negar a relevante função dos princípios constitucionais na determinação dos fins e objetivos a serem consi-

21 Segundo defende PRIETO SANCHÍS, o consequencialismo pode ser usado em qualquer processo de justificação jurídica, conjugando-se com outros argumentos ou métodos de interpretação, e não apenas naqueles casos difíceis em que não se encontra a solução por meio de "algum método hercúleo de interpretação dworkiniana”. PRIETO SANCHÍS, 1992, p. 171-72. 
derados na avaliação prospectiva dos resultados de uma decisão. Os objetivos e finalidades dispostos explícita ou implicitamente no sistema constitucional são veiculados por meio de princípios constitucionais, sendo imperioso que o cálculo consequencialista dos resultados de uma decisão judicial se formule à luz desses parâmetros, quer maximizando sua satisfação quer minimizando sua restrição.

\subsection{Argumentação de princípios e interpretação sistemática}

O componente principialista também está presente no método de interpretação sistemática. Além do critério de universalização e da argumentação consequencialista, o argumento da exigência de coerência da decisão judicial com o sistema jurídico em seu conjunto, sem sombra de dúvidas, representa uma das mais fecundas aplicações da argumentação de princípios. Aplicação que não se restringe à exigência de adequação ou correção lógica entre uma norma e o conjunto de normas do sistema, espraiando-se à necessidade de adequação teleológica, o ajuste substancial dos significados de uma disposição normativa com o ordenamento jurídico conjuntamente considerado. A interpretação sistemática impõe, portanto, coerência lógica e teleológica das normas aplicadas na decisão judicial.

A interpretação sistemática pode ser dividida em duas formas distintas: primeiramente, a "interpretação sistemática em um sentido estrito", conforme designada por ALEXY, com referência à correção lógica das normas no sistema jurídico, a adequação e coerência lógica de uma norma inserta no ordenamento jurídico (ALEXY, 2001, p. 232); afora o argumento sistemático, há o argumento teleológico sistemático, quando a interpretação sistemática é norteada à determinação da coerência material da disposição normativa com os fins dispostos no ordenamento. Neste sentido, pode-se dizer que o Direito é um sistema normativo que corresponde a um projeto racional 
do legislador, sendo a racionalidade do sistema jurídico uma espécie de diretriz (CALSAMIGLIA, 1988, p. 96-99).

A junção da interpretação sistemática propriamente dita, ou seja, a correção lógica das normas ao ordenamento normativo, com a interpretação teleológica, a argumentação destinada à aferição da coerência material das normas e a aptidão de seus significados à satisfação dos fins do sistema jurídico, conduz à interpretação principiológica, que determina seja a Constituição aplicada e interpretada como um todo integrado e inseparável, não em partes isoladas e descontextualizadas.

Em sede de uma argumentação principialista, os princípios constitucionais funcionam como razões de correção que permitem justificar - lógica e teleologicamente - uma decisão que aplique ou afaste determinada disposição normativa. A interpretação sistemática possibilita a determinação racional das normas ou grupos de normas que devem ser aplicados na decisão de certo problema prático.

Desta forma, pode-se dizer que "os princípios desempenham uma função essencial na construção do sistema ou, talvez melhor, que as chaves valorativas e axiológicas que definem e dotam de caráter próprio o sistema são justamente os princípios" (PRIETO SANCHÍS, 1992, p. 183).

\section{CONCLUSÃO}

A consolidação de um modelo de sistema normativo formado por regras e princípios jurídicos representa, inelutavelmente, um traço evolutivo do novo constitucionalismo sobre o positivismo jurídico contemporâneo. $\mathrm{O}$ reconhecimento da normatividade dos princípios contribui para a estruturação de um conceito de sistema jurídico marcado pela inter-relação axiológica e teleológica de princípios constitucionais e valores fundamentais. Um modelo de ordenamento jurídico que se apresenta aberto, dinâmico e coerente, informado pelo constante processo dialógico entre o Direito e a realidade social, 
bem como pela imposição aos poderes constituídos, enquanto função precípua, da satisfação e defesa dos princípios e objetivos fundamentais do Estado constitucional de direito.

Os princípios constitucionais desempenham uma função fundamental no ordenamento, conferindo-lhe adequação valorativa, ordenação axiológica e unidade interior. São suas pautas basilares e norteadoras, de onde decorrem os atributos de abertura e dinamicidade do sistema, vias pelas quais a moralidade se espraia a todos os confins do Direito. Os princípios explícitos e implícitos devem ser entendidos como os canais de inter-relação entre o Direito e a moral, as janelas por meio das quais ocorre o efetivo diálogo entre o ordenamento jurídico e a realidade social.

Um sistema jurídico informado por uma adequada teoria dos princípios, certamente, consegue fazer frente aos principais inconvenientes daquele modelo de sistema puro de regras jurídicas. O problema das lacunas de abertura, o afastamento da interpretação teleológica e a mitigada força normativa dos direitos fundamentais, são questões satisfatoriamente resolvidas no seio de um sistema de regras e princípios.

Por outro lado, a superação dos problemas do modelo puro de regras traz consigo outras adversidades próprias do sistema compartilhado, sobretudo a questão das lacunas de indeterminação, já que o fechamento sistemático oferecido pela teoria dos princípios seria apenas aparente. A indeterminação, a insegurança e o decisionismo talvez sejam os principais problemas a serem enfrentados pela teoria dos princípios, umas das bases instrumentais do pós-positivismo jurídico.

Abstract: The study addresses the contours of neoconstitutionalism, theoretical model that proposes to overcome the set of theories that mark the legal positivism, from the consolidation of a model based on the prevalence of the Constitution, the close relationship between moral reasoning and legal discourse, all informed by firm defense of normative force of constitutional prin- 
ciples. In the neoconstitutionalism, the theory of constitutional principles attains special significance for contemporary legal discourse, to be accompanied by a sound theory of legal reasoning, capable of ensuring rational criteria in the application of that open system of constitutional principles essential factor of legitimization and justification of decisions (judicial discourse). These are some of the discussions included in this study. Finally, we conclude defending the relevance as well, including the consolidation of a culture of defense of the Constitution.

Keywords: Neoconstitutionalism. Legal post-positivism. Constitutional principles. Legal argumentation.

\section{REFERÊNCIAS}

ALEXY, Robert. Derechos, razonamiento jurídico y discurso racional. Traducción de Pablo Larrañaga. Revista de Teoría y Filosofía del Derecho, n. 01, Alicante: Isonomia, 1994.

Sistema jurídico, principios jurídicos y razón práctica.

Taducción de Manuel Atienza. Cuadernos de Filosofía del Derecho, n. 05, Alicante: Doxa, 1988.

Teoria da argumentação jurídica. A teoria do discurso racional como teoria da justificação jurídica. Tradução de Zilda Hutchinson Schild Silva. São Paulo: Landy, 2001.

. Teoría de los derechos fundamentales. Traducción de Ernesto

Garzón Valdés. Madrid: Centro de Estudios Constitucionales, 1993.

ATIENZA, Manuel. Entrevista a Robert Alexy. Cuadernos de Filosofía del Derecho, n. 24, Alicante: Doxa, 2001.

ATIENZA, Manuel e RUIZ MANERO, Juan. Sobre principios y reglas. Cuadernos de Filosofía del Derecho, n. 10, Alicante: Doxa, 1991.

ÁVILA, Humberto. Teoria dos princípios: da definição à aplicação dos princípios jurídicos. 4. ed. São Paulo: Malheiros, 2004. 
BONAVIDES, Paulo. Curso de Direito Constitucional. 10. ed. São Paulo: Malheiros, 2000.

CADEMARTORI, Sérgio. Estado de direito e legitimidade: uma abordagem garantista. 2. ed. Campinas (SP): Millennium, 2007.

CALSAMIGLIA, Albert. Prólogo: ensayo sobre Dworkin. In. DWORKIN, Ronald. Los derechos en serio. Traducción de Marta Guastavino. 2. ed. Barcelona: Ariel Derecho, 1989.

Introducción a la ciencia juridica. 2. ed. Barcelona: Ariel Derecho, 1988.

. Postpositivismo. Cuadernos de Filosofía del Derecho, n. 21-I, Alicante: Doxa, 1998.

CANOTILHO, José Joaquim Gomes. Direito Constitucional e teoria da Constituição. 7. ed. Coimbra: Almedina, 2003.

CARBONEL, Miguel (Coord.). Neoconstitucionalismo(s). 2. ed. Madrid: Trotta, 2005.

. Teoria del neoconstitucionalismo: ensaios escogidos. Madrid: trotta, 2007.

CARBONELL, Miguel; SALAZAR, Pedro (Coord.). Garantismo: estudios sobre el pensamiento juridico de Luigi Ferrajoli. Madrid: Trotta, 2005.

CRISTÓVAM, José Sérgio da Silva. Colisões entre princípios constitucionais: razoabilidade, proporcionalidade e argumentação jurídica. 1. ed. 4. tir. Curitiba: Juruá, 2011.

DWORKIN, Ronald. Los derechos en serio. Traducción de Marta Guastavino. 2. ed. Barcelona: Ariel Derecho, 1989.

FERRAJOLI, Luigi. Garantismo: una discusión sobre derecho y democracia. Madrid: Trotta, 2006.

. Derecho y razón: teoría del garantismo penal. 4. ed. Madrid: Trotta, 2000 .

- Principia iuris: teoria del diritto e della democrazia. Roma: Laterza, 2007. 
HABERMAS, Jurgen. ¿Como es posible la legitimidad por vía de legalidad? Traducción de Manuel Jiménez Redondo. Cuadernos de Filosofía del Derecho, n. 05, Alicante: Doxa, 1988.

HART, Herbert L. A. O conceito de Direito. Tradução de Armindo Ribeiro Mendes. 2. ed. Lisboa: Fundação Calouste Gulbenkian, 1996.

HESSE, Konrad. A força normativa da Constituição. Tradução de Gilmar Ferreira Mendes. Porto Alegre: Sergio Antonio Fabris Editor, 1991.

LARRAÑAGA, Pablo. Sobre la teoría del Derecho de Robert Alexy. Revista de Teoría y Filosofía del Derecho, n. 01, Alicante: Isonomia, 1994.

LOCKE, John. Dois tratados sobre o governo. Tradução de Júlio Fischer. São Paulo: Martins Fontes, 1998.

PECZENIK, Aleksander. Dimensiones morales del Derecho. Traducción de Juan A. Pérez Lledó. Cuadernos de Filosofía del Derecho, n. 08, Alicante: Doxa, 1990.

PRIETO SANCHÍS, Luis. Sobre principios y normas: problemas del razonamiento jurídico. Madrid: Centro de Estudios Constitucionales, 1992.

RAMÓN DE PÁRAMO, Juan. Entrevista a H. L. A. Hart. Cuadernos de Filosofia del Derecho, n. 05, Alicante: Doxa, 1988.

RAWLS, John. Uma teoria da justiça. Tradução de Almiro Pisetta e Lenita M. R. Esteves. São Paulo: Martins Fontes, 1997.

SARLET, Ingo Wolfgang. A eficácia dos Direitos Fundamentais. 4. ed. Porto Alegre: Livraria do Advogado, 2004.

SARMENTO, Daniel. O neoconstitucionalismo no Brasil: riscos e possibilidades. In: LEITE, George Salomão; SARLET, Ingo Wolfgang (Org.). Direitos Fundamentais e Estado Constitucional: estudos em homenagem a J. J. Gomes Canotilho. São Paulo; Coimbra: Revista dos Tribunais; Coimbra Editora, 2009.

STRECK, Lenio Luiz. Verdade e consenso. 4 ed. São Paulo: Saraiva, 2011.

WOLKMER, Antonio Carlos. Pluralismo Jurídico: fundamentos de uma nova cultura no direito. 3. ed. São Paulo: Alfa Ômega, 2001.

ZAGREBELSKI, Gustavo. El derecho ductil: ley, derecho y justicia. Traducción de Marina Gascón, Madrid: Trota, 1995. 